Philip G. Oguntunde | Babatunde J. Abiodun | Gunnar Lischeid | Abayomi A. Abatan

\title{
Droughts projection over the Niger and Volta River basins of West Africa at specific global warming levels
}

Suggested citation referring to the original publication:

International Journal of Climatology 40 (2019) 13,

DOI https://doi.org/10.1002/joc.6544

Postprint archived at the Institutional Repository of the Potsdam University in:

Zweitveröffentlichungen der Universität Potsdam : Mathematisch-Naturwissenschaftliche Reihe 1203

ISSN: $1866-8372$

https://nbn-resolving.org/urn:nbn:de:kobv:517-opus4-525943

DOI: https://doi.org/10.25932/publishup-52594 



\title{
Droughts projection over the Niger and Volta River basins of West Africa at specific global warming levels
}

\author{
Philip G. Oguntunde ${ }^{1,2}$ \\ Abayomi A. Abatan 5 \\ Babatunde J. Abiodun ${ }^{3}$ ( ) | Gunnar Lischeid ${ }^{2,4}$ |
}

${ }^{1}$ Department of Agricultural and Environmental Engineering, Federal University of Technology, Akure, Nigeria

${ }^{2}$ Leibniz Centre for Agricultural

Landscape Research, Müncheberg,

Germany

${ }^{3}$ Department of Environmental and Geographical Science, University of Cape Town, Cape Town, South Africa

${ }^{4}$ Institute of Earth and Environmental Science, University of Potsdam, Potsdam, Germany

${ }^{5}$ School of Geosciences, University of Edinburgh, Edinburgh, UK

\section{Correspondence}

Philip G. Oguntunde, Department of Agricultural and Environmental Engineering, Federal University of Technology, Akure, Nigeria.

Email: pgoguntunde@futa.edu.ng

Funding information

Water Research Commission; National Research Foundation

\begin{abstract}
This study investigates possible impacts of four global warming levels (GWLs: GWL1.5, GWL2.0, GWL2.5, and GWL3.0) on drought characteristics over Niger River basin (NRB) and Volta River basin (VRB). Two drought indicesStandardized Precipitation Index (SPI) and Standardized PrecipitationEvapotranspiration Index (SPEI) - were employed in characterizing droughts in 20 multi-model simulation outputs from the Coordinated Regional Climate Downscaling Experiment (CORDEX). The performance of the simulation in reproducing basic hydro-climatological features and severe drought characteristics (i.e., magnitude and frequency) in the basins were evaluated. The projected changes in the future drought frequency were quantified and compared under the four GWLs for two climate forcing scenarios (RCP8.5 and RCP4.5). The regional climate model (RCM) ensemble gives a realistic simulation of historical hydro-climatological variables needed to calculate the drought indices. With SPEI, the simulation ensemble projects an increase in the magnitude and frequency of severe droughts over both basins (NRB and VRB) at all GWLs, but the increase, which grows with the GWLs, is higher over NRB than over VRB. More than $75 \%$ of the simulations agree on the projected increase at GWL1.5 and all simulations agree on the increase at higher GWLs. With SPI, the projected changes in severe drought is weaker and the magnitude remains the same at all GWLs, suggesting that SPI projection may underestimate impacts of the GWLs on the intensity and severity of future drought. The results of this study have application in mitigating impact of global warming on future drought risk over the regional water systems.
\end{abstract}

\section{KE YWOR D S}

climate change, drought index, global warming levels, river basins, West Africa, CORDEX data

\section{1 | INTRODUCTION}

West Africa is a drought prone region. In this region, any substantial rainfall deficit usually devastates socioeconomic activities for a long period, because agriculture, hydro-electric power, and river basin management depend on rainfall. For instance, the decrease of rains in the 1970s (Hulme, Doherty, Ngara, New, \& Lister, 2001; Kasei, Diekkrüger, \& Leemhuis, 2010; Oguntunde, Abiodun, \& Lischeid, 2017; Oguntunde, Lischeid, \& Abiodun, 2018; van de Giesen, Liebe, \& Jung, 2010) has caused substantial modifications in land and water 
management practices in the region in the past decades (Ogilvie et al., 2010; van de Giesen et al., 2010). Future changes in climate are projected to affect the characteristics of extreme events depending on the magnitude and direction of change (Alfieri et al., 2017; IPCC, 2007, 2014). West Africa has been projected as a vulnerable region (IPCC, 2007; Ogilvie et al., 2010). As most people in West Africa are involved in climate-sensitive sectors of the economy, any future change in climate that encourages drier condition may increase the vulnerability of climate risks over the region. Therefore, to facilitate vulnerability assessment and impacts, there is a need to investigate and understand the characteristics of future climate in the region, especially over the basin levels.

Niger River basin (NRB) and Volta River basin (VRB) are the two largest river basins in West Africa. They play important roles in the regional socioeconomic sustainability. Any negative impact of climatic change on the water systems will take a toll on the livelihoods of the people. Accordingly, studies that improve understanding of the roles of extreme climate events (droughts) in moderating regional hydrology are very essential. In fact, basin-wide studies to understand the influence of global environmental change on hydrology have become relevant in recent times owing to numerous anxieties raised about possible modifications of the earth's climate at various levels (e.g., Kasei et al., 2010; Ogilvie et al., 2010; van de Giesen et al., 2010). Previous studies showed that major river basins in West Africa, including NRB and $\mathrm{VRB}$, have been experiencing water stress resulting from both natural and anthropogenic influences (e.g., Adeyeri, Lawin, Laux, Ishola, \& Ige, 2019; Laux, Kunstmann, \& Bárdossy, 2008; Oyerinde et al., 2015; Sylla, Pal, Faye, Dimobe, \& Kunstmann, 2018). Sylla et al. (2018) brought the attention of the research community to the impact of warming level on the future of the West African basinscale irrigation. Their study projected that West African river basins will witness severe freshwater shortages under 2 and $1.5^{\circ} \mathrm{C}$ global warming scenarios. Using indigenous perception method to analyse the impact of climate change on hydroclimate over Malanville (Benin) and Kainji (Nigeria) dams, Oyerinde et al. (2015) concluded that integration of indigenous knowledge into climate change science could lessen the effects of deteriorating hydroclimatic observations and enhance sustainable adaptations. However important this indigenous perception may be, it lacks scientific background and could not give any information about the future of the basins. Although Sylla et al. (2018) addressed the potential impact of future warming scenarios on the hydroclimatology of the West African river basins, they only focused on basin potential without consideration of the impact of drought, a major extreme climate event that can significantly impact water resources. In addition, they only considered the simulations based on the Representative Concentration Pathways 4.5 (RCP4.5), which is not as impactful as the RCP8.5.

Some studies have used both observations and climate model simulations to examine past characteristics of rainfall or droughts over West Africa and how changes in climate may influence the future characteristics (Diasso \& Abiodun, 2017; Kasei et al., 2010; Laux et al., 2008; Oguntunde, Friesen, van de Giesen, \& Savenije, 2006; Oguntunde et al., 2017, 2018). While the results of these studies could guide on sustainable use and management of land and water resources, they are not in line with the United Nations Framework Convention on Climate Change 21st Conference of Parties Paris Agreement, where agreement was made to stabilize increase in the mean temperature to less than $2.0^{\circ} \mathrm{C}$ above pre-industrial levels and to struggle for the possibility of limiting the increase in temperature to $1.5^{\circ} \mathrm{C}$. Hence, these studies could not provide the needed information on how the characteristics of droughts could change under specific global warming levels. In addition, the results of most of these studies are based on simulations of a single regional climate model (RCM) in downscaling of global climate models (GCMs; Oguntunde et al., 2018), with attendant limitations for uncertainty sampling in the projections. The fewer recent studies that used multiRCMs to project impacts of climate change on rainfall at specific global warming levels $\left(1.5\right.$ and $2.0^{\circ} \mathrm{C}$, in the framework of Paris Agreement) have focused on different characteristics such as start and end of the rains and growing season length (Kumi \& Abiodun, 2018), seasonal rainfall, and cumulative dry days (Klutse et al., 2018), without providing any information on droughts over the river basins. More recently, Abiodun, Makhanya, Petja, Abatan, and Oguntunde (2018) quantified the impacts of climate change on droughts over southern African river basins at specific GWLs and showed how different drought projections can be utilized in managing water resources over the basins. However, the drought projections over southern African basins cannot be linearly transferred or applied over the West African region, because of differences in atmospheric circulation and climate.

This study aims to advance the study of Sylla et al. (2018) by extending the work of Abiodun et al. (2018) to West African river basins. Specifically, the study examines and compares the impact of projected drought at 1.5, $2.0,2.5$, and $3.0^{\circ} \mathrm{C}$ GWLs over the two prominent river basins in West Africa (NRB and VRB). As the remaining parts of this study, the data and methods are presented in section 2; the results are presented in section 3, while the discussion and conclusion are presented in section 4 . 


\section{2 | DATA AND METHODS}

\section{1 | The study domain}

The NRB and VRB in West Africa provide sources of livelihood for the fast population of people inhabiting the riparian countries enclosed within their catchments. The NRB is the second largest basin in Africa and is enclosed within $5^{\circ}-24^{\circ} \mathrm{N}$ and $12^{\circ} \mathrm{W}-17^{\circ} \mathrm{E}$. Precipitation varies from about $250 \mathrm{~mm} \cdot \mathrm{year}^{-1}$ at the desert zone to over 2,000 mm.year ${ }^{-1}$ near the coastal zone (Andersen, Dione, Jarosewich-Holder, \& Olivry, 2005; Oguntunde et al., 2018). The VRB is shared by six countries. It enclosed an area bounded within $5^{\circ}-14^{\circ} \mathrm{N}$ and $2^{\circ} \mathrm{E}-5^{\circ} \mathrm{W}$. Precipitation similarly shows a very strong north-south gradient (Kasei et al., 2010; Laux et al., 2008). All the riparian countries in the two basins have been undergoing rapid socioeconomic development, with significant population increase and intensified land use (Ogilvie et al., 2010). The map of the two river basins in West Africa is shown in Figure 1, while their characteristics are presented in Table 1.

\section{2 | Datasets}

We analysed observed and simulated climate datasets for the study. The observed climate dataset is the Climate Research Unit (CRU) gridded climate data (TS version 4.01) described in Harris et al. (2014). This highresolution $(0.5 \times 0.5)$ monthly dataset covers global land mass and extends from 1901 to 2016. However, only the data for 1971-2000 were analysed in the present study. We chose CRU observation dataset to evaluate the

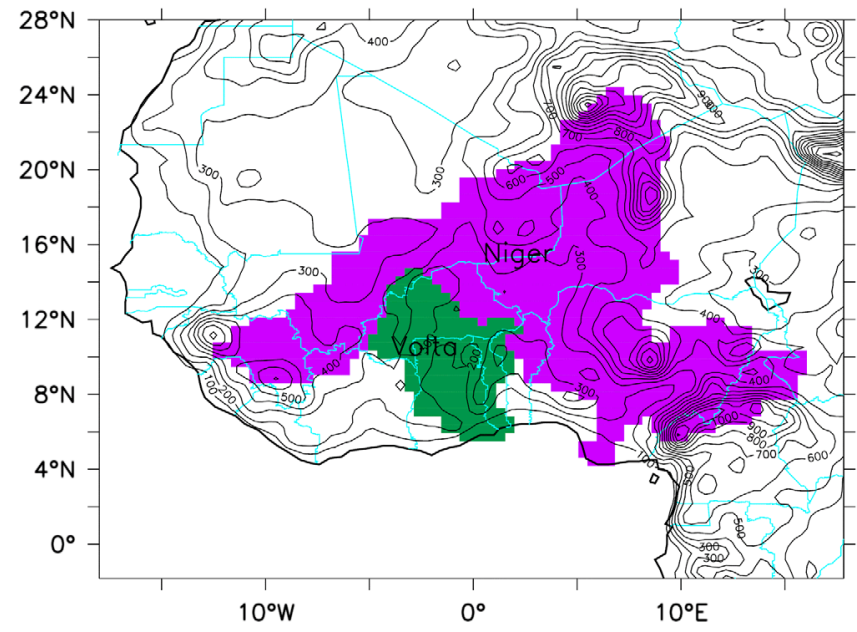

FI G URE 1 The study domain showing West African topography with Niger and Volta River basins of West Africa [Colour figure can be viewed at wileyonlinelibrary.com] simulations because it has all the variables (precipitation, TMAX, and TMIN) needed for calculating both drought indices. Other datasets (GPM, GPCC, EOBS, etc.) have only precipitation data. The simulated climate dataset consists of 20 regional climate simulations from the Coordinated Regional Climate Downscaling Experiment (CORDEX; Nikulin et al., 2018). As part of CORDEX activities, the simulations were obtained by using eight RCMs to dynamically downscale past and future climate simulations (1950-2100) from 12 GCMs over Africa at the horizontal resolution of $0.44 \times 0.44^{\circ}$. However, this study used a subset of the simulations (Table 2). The simulation datasets were based on the RCP8.5 "business as usual" scenario (Riahi et al., 2011). The specific global warming levels were focused in line with the recent COP21 Paris agreement (UNFCCC, 2015). The period of the warming level differs with GCMs and RCPs.

\section{3 | Methods}

The methodology used in analysing the datasets is the same as in Abiodun et al. (2018). Droughts are characterized over the basins with two indices: the Standardized Precipitation Index (SPI) and the Standardized Precipitation-Evapotranspiration Index (SPEI). The two indices are well known for studying droughts (e.g., Abatanet al., 2017a, b; Abiodun et al., 2018; Guttman, 1998, 1999). SPI was formulated as a probability-based index that uses only precipitation $(P)$ to calculate the drought index (McKee, Doesken, \& Kleist, 1993). Details of equations and parameters for drought index formulation and computation can be found in previous reports (e.g., Lloyd-Hughes \& Saunders, 2002; McKee et al., 1993; Oguntunde et al., 2017, 2018). Like SPI, the SPEI is computed using climatic water balance data instead of precipitation data (Vicente-Serrano, Beguería, \& LópezMoreno, 2010). Given that the potential evapotranspiration (PET) is atmospheric evaporative demand, its inclusion in computation of SPEI may help capture global warming effects or impacts. Thus, Vicente-Serrano et al. (2010) argued that for drought identification, SPEI may be more appropriate than SPI.

The climate water balance $\left(\mathrm{CWB}_{i}\right)$ for the month $i$ is calculated as

$$
\mathrm{CWB}_{i}=P_{i}-\mathrm{PET}_{i} .
$$

The PET was calculated using the Hargreave method (HG; Hargreaves \& Samani, 1985). Due to its comprehensive theoretical base, the Penman-Monteith (PM) method is usually preferred for calculation of PET. However, the PM methods requires several climate 
TA B LE 1 Brief characteristics of the Niger and Volta River basins of West Africa

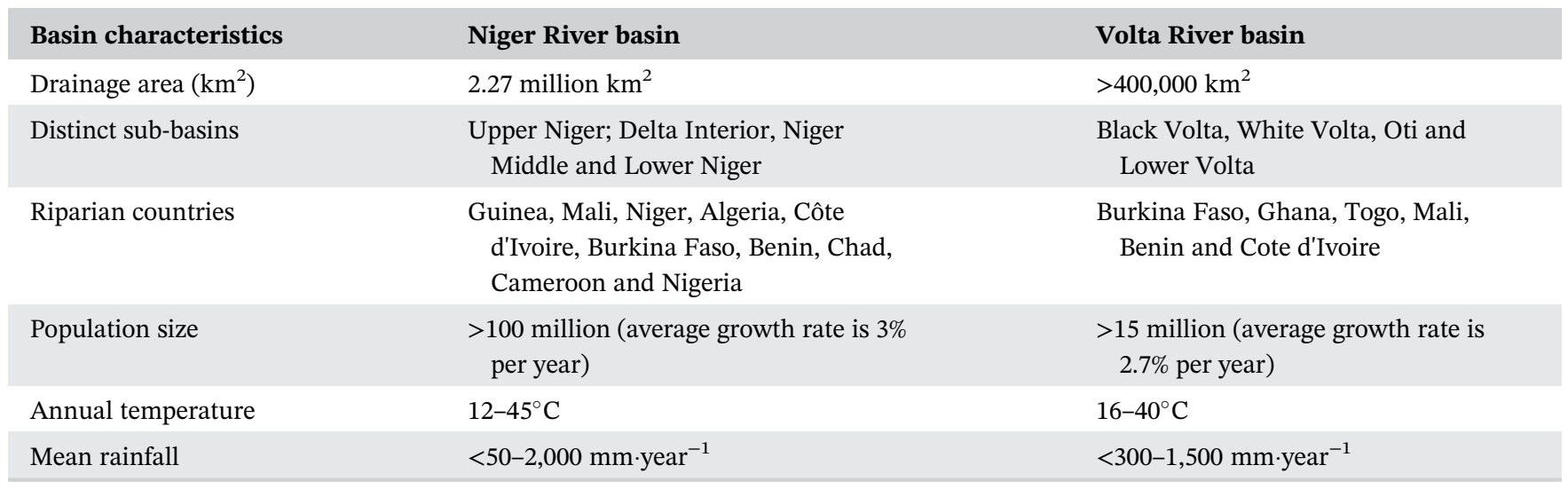

Source: Andersen et al. (2005), van de Giesen et al. (2010), and Ogilvie et al. (2010).

T A B L E 2 The names of GCMs and the downscaling RCMs for the simulations used in the study

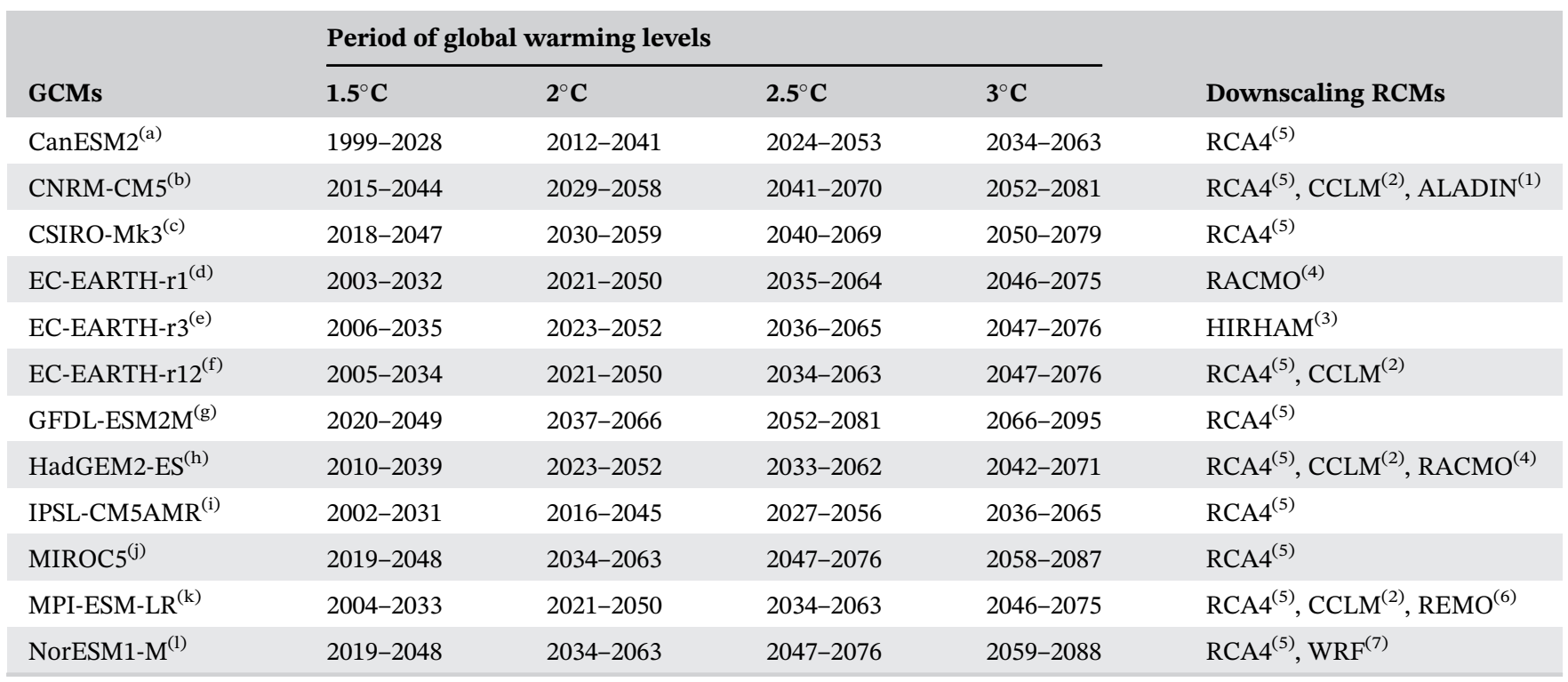

Note: The corresponding 30-year period for various global warming levels $\left(1.5,2,2.5\right.$, and 3.0 $\left.{ }^{\circ} \mathrm{C}\right)$ are indicated. More detailed information on the GCMs, RCMs, and method for calculating the periods are in the alphabets (a-l) and numbers (1-6) in brackets of the GCMs and RCMs, respectively, are used tags to represent the simulations (e.g., a5 represents CanESM2_RCA4 simulation).

variables (i.e., air temperature, relative humidity, solar radiation, and wind speed), some of which there are no reliable data for over the study region. However, unlike $\mathrm{PM}$, the HG method requires only temperature (maximum and minimum) for calculating the PET. Several studies (e.g., Beguería, Vicente-Serrano, Reig, \& Latorre, 2014; Droogers \& Allen, 2002) have shown that HG method gives comparable results with the PM method in different parts of the world and Beguería et al. (2014) has recommended the use of HG for calculating PET where there is no sufficient data for the PM method.

Using monthly precipitation and temperature (maximum and minimum) from simulation (CORDEX) and observation (CRU) data as input to SPEI and SPI algorithms in R package (Beguería et al., 2014), we calculated the observed and simulated 12-month SPEI and SPI for each month of the years. Details on how to calculate SPI and SPEI are contained in Beguería et al. (2014). Generally, the values of the drought indices range for -2.5 (extreme drought condition) to +2.5 (extreme wet condition). The focus of the present study is the magnitude and frequency of severe drought. A severe drought event is said to occur in a month if the 12-drought index (SPI or SPEI) for the is less than -1.5; the absolute value of the drought index for the event is regarded as the severe drought magnitude (SDM) while the number of months the event occurs in a year (or a decade) is regarded as severe drought frequency (SDF). In the study, all 
the variables calculated or derived from the CRU observation data are referred to as observed variables while those obtained from the CORDEX simulation are called simulated variables.

Performance evaluation of the simulation datasets over West Africa was carried out by comparing the simulated and observed climate data for the reference period (1971-2000). The performance evaluation focused on the climate variables needed for calculating SPI and SPEI. The future climate simulation data were extracted for the four GWL periods (i.e., 1.5, 2.0, 2.5, and $3.0^{\circ} \mathrm{C}$; hereafter, GWL1.5, GWL2.0, GWL2.5, and GWL3.0, respectively). Following Nikulin et al. (2018), we defined a GWL period as a 30-year window for which the global mean temperature (climatology) is warmer, that is, the pre-industrial climate (1861-1890) by the targeted GWL values. Table 2 shows the GWL periods obtained for each GWL in all simulation datasets. The climate change at each GWL is calculated as the difference between the climatology of the reference period (1971-2000) and the GWL periods (i.e., GWL minus reference).

Two approaches were used to assess the robustness of the projected climate change. The first approach examines the statistical significance of projected changes. The change is robust if more than $75 \%$ of the simulations indicate that the climate change is statistically significant (at $99 \%$ confidence level; using a $t$ test, with respect to the climate variability of the reference period). The second approach uses boxplot to examine the agreement of simulations on projected sign of the change. The change is robust if more than $75 \%$ of the simulations agree on the sign of the projected changes.

\section{3 | RESULTS}

\section{1 | Evaluation of climate simulations over the basins}

In this section, we assess the performance of CORDEX RCMs simulations to reproduce the observed climate variables over the two River basins. The climate variables considered include temperatures, PRE, PET, and CWB. The assessment of these climate variables is very important because the accuracy and reliability of the future simulations of the drought indices depend on how well the models capture the historical climate variables. The results of the evaluation are presented in Figures 2-5.

The spatial distributions of observed and simulated surface air temperatures and their biases are presented in Figure 2. The observed CRU TMAX shows a zonal pattern that increases northwards from the Guinea coast (Figure 2a). This zonal distribution places the centre of TMAX over the Sahel-Sahara region at about $12^{\circ}-20^{\circ} \mathrm{N}$. As a result, the northwestern region of the NRB is warmer than every other region of the basins. The spatial pattern of the simulated ensemble mean (RMEAN) TMAX is similar to observed TMAX (Figure $2 b$ ). The thermal peak is limited to the western Sahel and it is an order of about $2^{\circ} \mathrm{C}$ lower than observation. The statistical
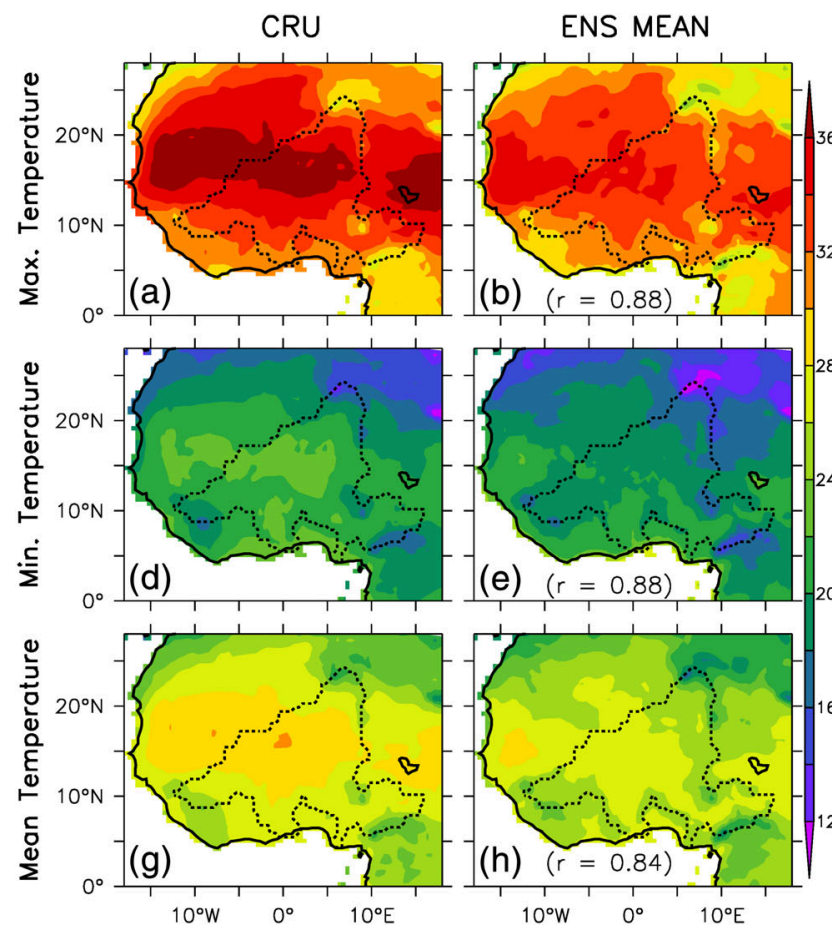

BIAS

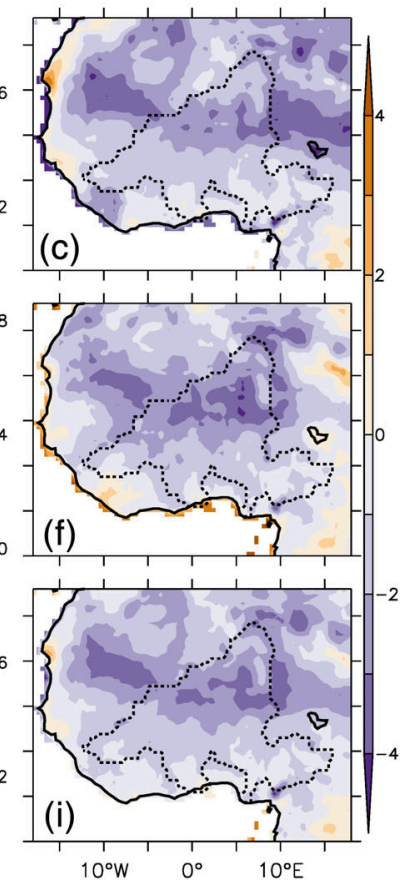

F I G URE 2 Climatology of observed (CRU) and simulated (RCM) maximum, minimum, and mean temperatures (TMAX, TMIN, and TMEAN, respectively; ${ }^{\circ} \mathrm{C}$ ) over West Africa during 1970-2005. The outline of the Niger and Volta River basins are indicated by the dashed black and green contours, respectively. The spatial patterns of observed values are shown in the first column, ensemble mean (ENS MEAN) in the middle, and the simulation biases (BIAS: ENS MEAN minus CRU) are in the third column [Colour figure can be viewed at wileyonlinelibrary.com] 
F I G URE 3 Simulated and observed spatial patterns of the hydrometeorological variable necessary for drought computation over the West Africa including Niger and Volta River basins (climatology, 1970-2005). The climate variables are precipitation (PRE; mm. month ${ }^{-1}$; panels a-c, respectively); PET (mm.month ${ }^{-1}$; panels d-f, respectively), and climate water balance (CWB; PRE minus PET; $\mathrm{mm} \cdot \mathrm{month}^{-1}$; panels g-i, respectively). The observed values are shown in first column, ensemble mean (RMEAN) in the middle while the BIAS (RMEAN minus CRU) is in the third column [Colour figure can be viewed at wileyonlinelibrary.com]
FI G URE 4 Simulated and observed annual cycle of the climate variable necessary for drought computation over the Niger and Volta River basins (climatology, 1970-2005). The climate variables are temperature (TMIN and TMAX; panels a,b); precipitation and potential evapotranspiration (PRE and PET; panels c,d); and climate water balance (CWB: PRE minus PET; panels e,f). The shading shows the range between the maximum and minimum, while the continuous thick line shows the ensemble mean (ENS MEAN) and the dashed line indicates the CRU observation [Colour figure can be viewed at wileyonlinelibrary.com]
CRU
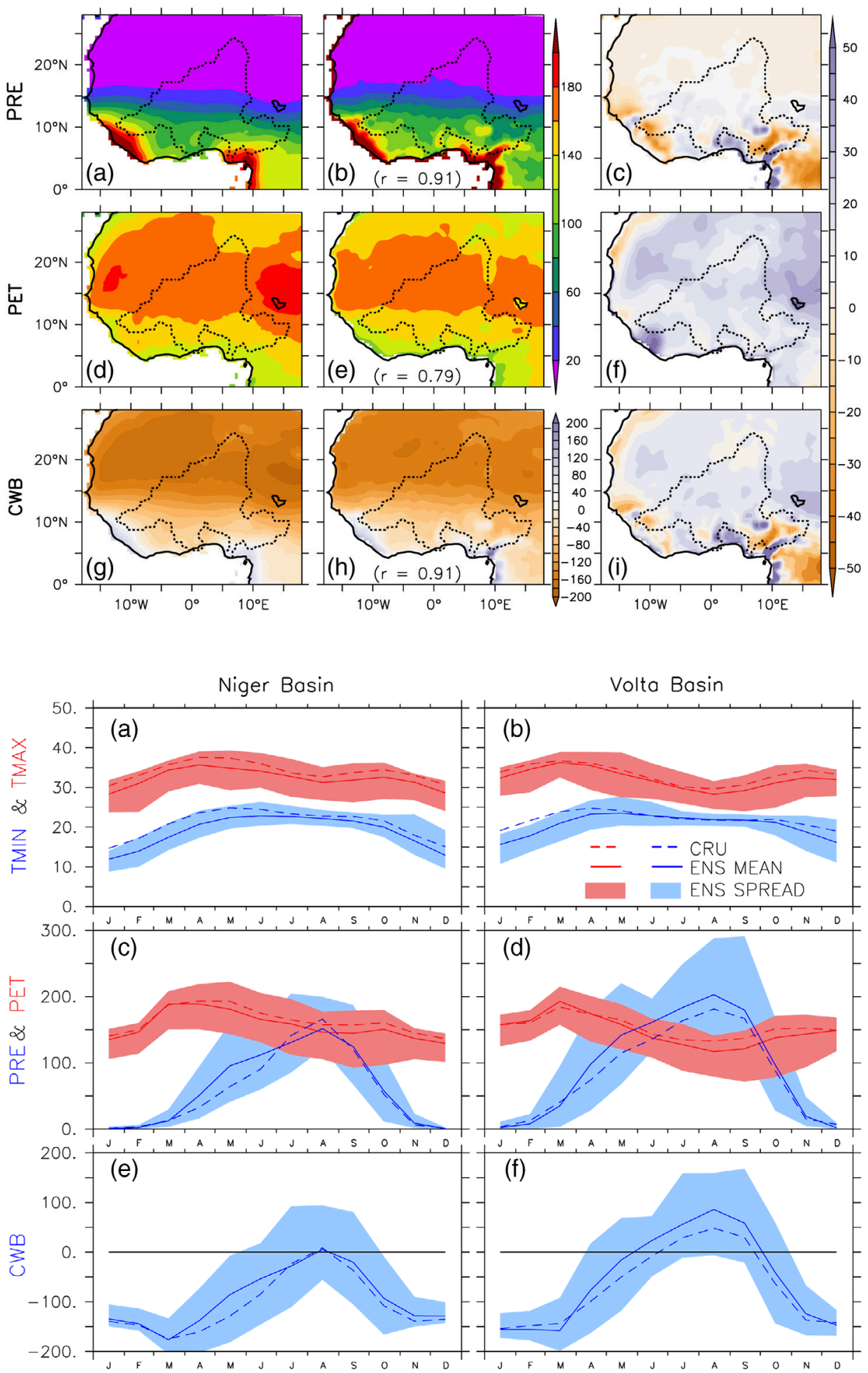

comparison of the observed and simulated TMAX through the pattern correlation is high, and it indicates that the model captures the spatial pattern of observed TMAX well (i.e., $r=.88$ ). The agreement between the observed and simulated TMAX comes from the ability of the model in simulating peak in TMAX south of $12^{\circ} \mathrm{N}$. This is obvious in the bias pattern that ranges between
0 and $2^{\circ} \mathrm{C}$ over the Guinea coast. The largest bias is observed north of $20^{\circ} \mathrm{N}$ (Figure 2c). As indicated in Figure 2 d,e, the spatial patterns of observed and simulated TMIN are slightly similar with a pattern correlation of .89 although the CORDEX models underestimate temperature over the Sahel region. However, CORDEX models generally underestimate TMIN by about $1-2^{\circ} \mathrm{C}$ in 


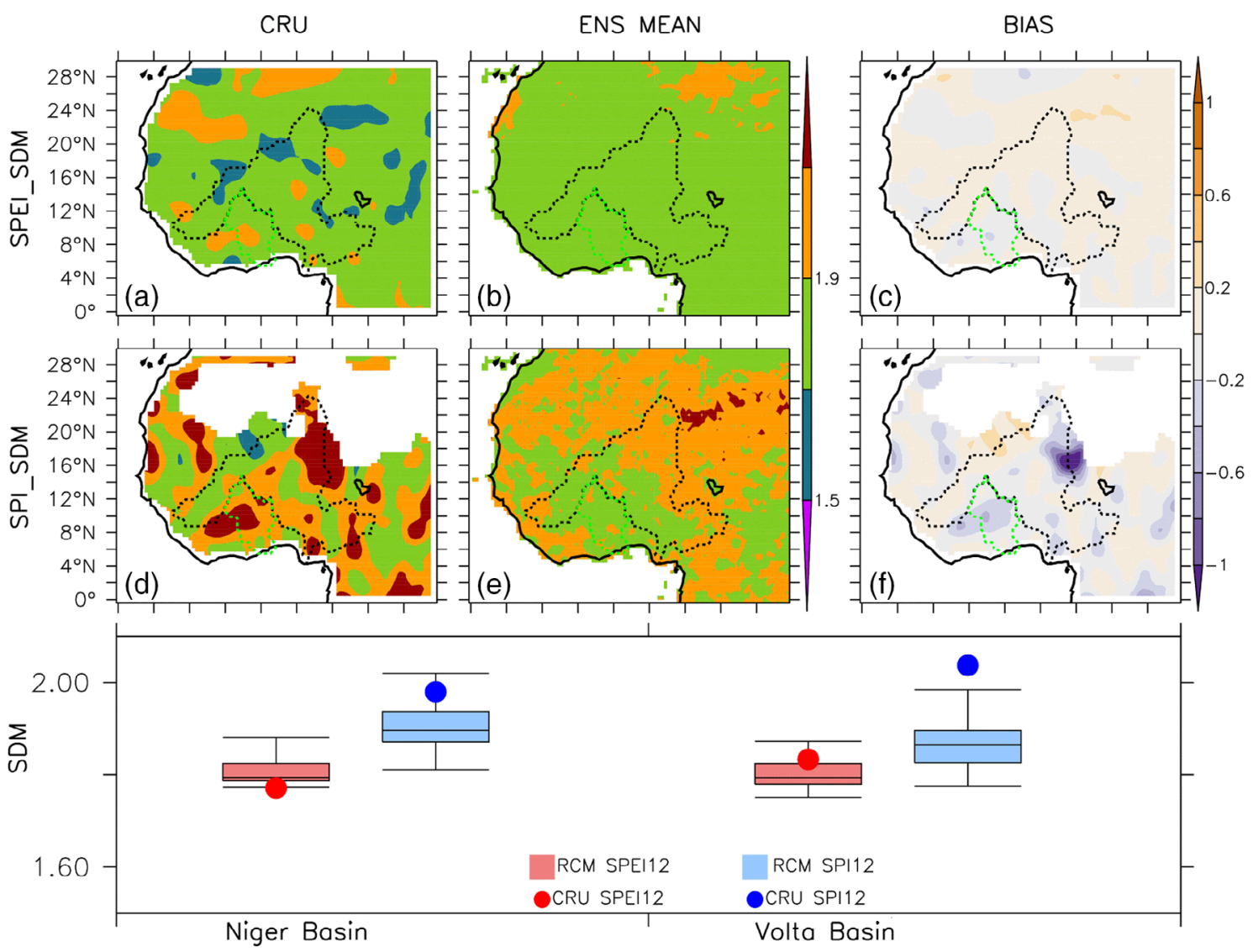

F I G U R E 5 Severe drought magnitude (SDM) for 12-month SPEI and SPI (i.e., SPEI12_SDM and SPI_SDM) as observed (CRU) and simulated (ENS MEAN) during the reference period (1971-2000) over the Niger and Volta River basins. A severe drought occurs when the value of 12-month drought index (SPEI12 or SPI12) is less than -1.5 [Colour figure can be viewed at wileyonlinelibrary.com]

most parts of $\mathrm{NRB}$ and by about $1^{\circ} \mathrm{C}$ in the VRB (Figure 2f). As in the spatial distributions of observed TMAX and TMIN, observed TMEAN is characterized by zonal band of maximum TMEAN $\left(>28^{\circ} \mathrm{C}\right)$ spanning the Sahara-Sahel region, with lowest values between 24 and $28^{\circ} \mathrm{C}$ over the Guinea coast (Figure $2 \mathrm{~g}$ ). The temperature minima are located over Cameroon Mountains adjacent to Calabar, Jos Plateau, and the Guinea Highlands, while the temperature maxima are located over the Saharan heat low region, consistent with the literature. The models exhibit the ability to reproduce the spatial distribution of observed TMEAN although there are some differences both in magnitude and size (Figure 2h). The similarity in patterns results in a pattern correlation of about .84. The lower values over the orographic regions are well captured, while the models underestimate the magnitude of the TMEAN over the Saharan heat low. As a result, a cold bias in excess of $2^{\circ} \mathrm{C}$ is observed over the Sahara region.

The observed and simulated spatial distribution of rainfall, PET, and CWB are shown in Figure 3. The ensemble mean captures the spatial patterns of the rainfall, PET, and CWB very well. The rainfall distribution decreases northwards from the Guinea coast to the Sahel-Sahara region, with the lowest values $\left(<20 \mathrm{~mm} \cdot \mathrm{month}^{-1}\right)$ over the Sahara region. The pattern of the rainfall maxima over the Niger Delta and the Guinea highlands are equally well simulated although the magnitude is slightly underestimated. Therefore, the simulated rainfall exhibited $\pm 5 \%$ of observed rainfall in most parts of the basin with underestimation generally around the Guinea highlands and the Benue basin. The pattern correlation between observed and simulated rainfall is very high $(r=.92)$. The spread of monthly maximum PET is generally larger in the observation in comparison with the simulation with bias generally less than $10 \%$ in most part of the two basins. However, the pattern correlation between observed and simulated PET is very high $(r=.81)$. The CWB field showed similar spatial pattern as in rainfall and the pattern correlation between observed and simulated CWB is also very high $(r=.92)$. The bias in simulated CWB is about $+10 \%$ in most part of the basin with underestimation over the Benue basin. 
Figure 4 shows the observed and simulated seasonal cycle of climate variables over the study domain. The temporal patterns of these climatic variables indicated that the models performed very well, but with very slight differences in magnitude. For both observed and simulated TMIN and TMAX, the lowest temperatures occurred in January and February with the highest in April and May (Figure 4a,b). Similarly, the models captured the temperature drop in July and August. The drop in temperatures is probably due to higher cloudiness amount during these periods. Despite the similarities in temporal patterns of temperatures, the simulated TMIN showed large cold bias during the first 6 months (January-June); the upper quartile of the simulated TMIN is almost equal to the observed TMIN during January-May. However, the observed maximum temperature was located within the spread of the simulated values, with the simulated ensemble median slightly lower than observation.

The temporal patterns of observed rainfall indicated that rainfall increases steadily from January, reaching a peak in August, after which it decreases sharply (Figure 4c,d). This pattern is related to the seasonal match of the intertropical discontinuity over West Africa. The RCMs reproduce the seasonal cycle of observed rainfall over the two basins. The models are characterized by a single rainfall peak around August with values lower than the observed. Furthermore, during the first 6 months (January-June), simulated rainfall values are higher but slightly lesser than observed during the last 6 months (July-December). Comparing the seasonal patterns of PET from the RCMs with observation, it is shown that the models reproduce the seasonal cycle of this variable very well (Figure $4 c, d$ ). The PET is characterized by two maxima in March/May and October. The seasonal cycles of observed and simulated CWB for the two basins (Figure 4e,f) are like those of the rainfall. The RCMs reasonably reproduce the observed CWB, but the spread is wider. The simulated mean $\mathrm{CWB}$ are higher than observed CWB, especially for the months of March-July.

The 12-month timescale of observed and simulated drought intensity and frequency are shown in Figures 5 and 6. The observed and simulated mean drought intensity are comparable over the basins, but with slight differences in magnitude (Figures 5 and 6). Observed (red dot for SPEI and blue dot for SPI) and simulated (box plot)
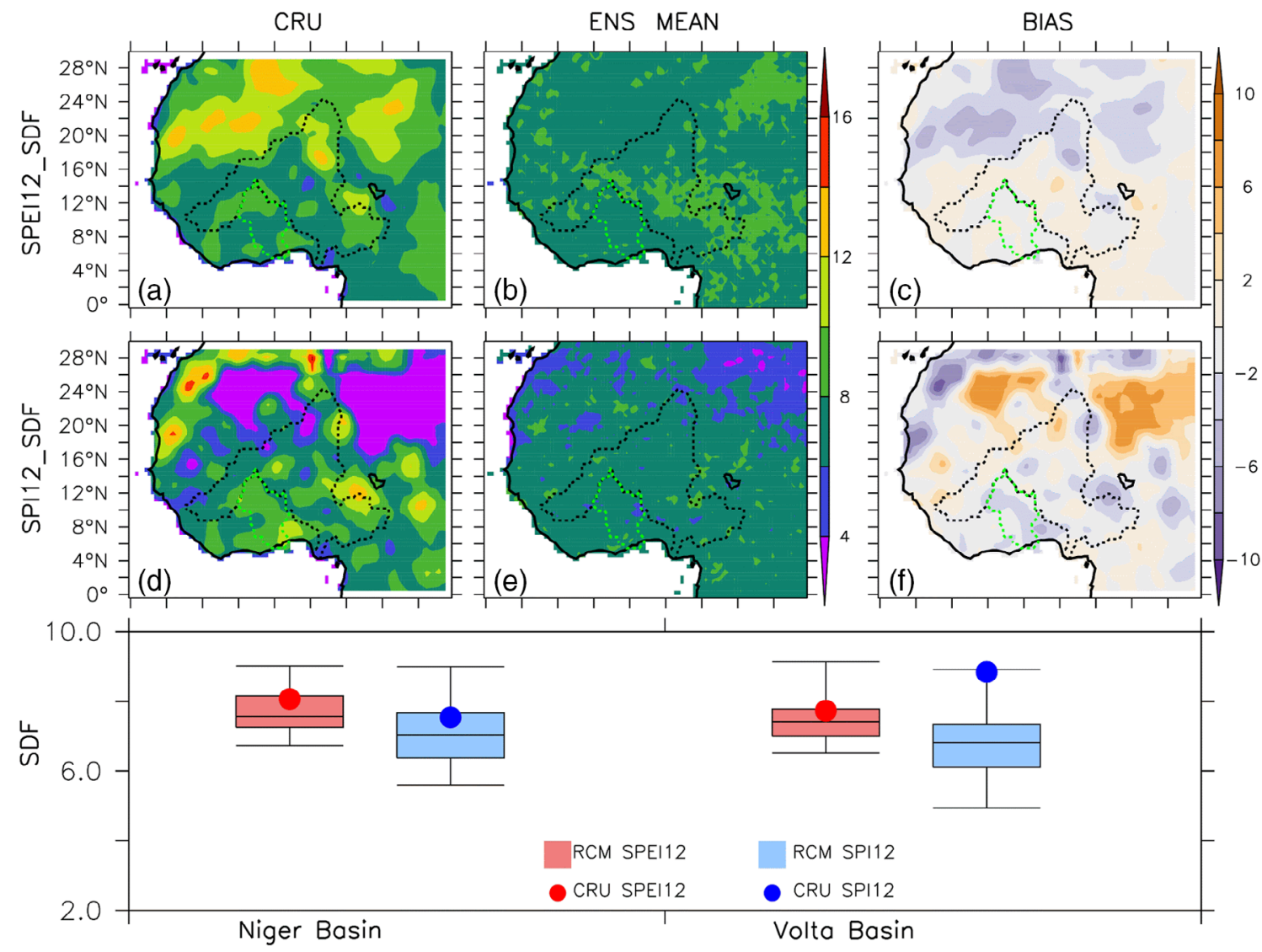

F I G U RE 6 SDF for 12-month SPEI and SPI (i.e., SPEI12_SDF and SPI_SDF) as observed (CRU) and simulated (ENS MEAN, RCM) during the reference period (1971-2000) over the Niger and Volta River basins. A severe drought occurs when the value of 12-month drought index (SPEI12 or SPI12) is less than -1.5 [Colour figure can be viewed at wileyonlinelibrary.com] 
drought frequency averaged over the Basins are shown in the lower panel of Figures 5 and 6 . For both basins, the observed values are generally located within the spread of the models with the observed values in the fourth quartile for SPEI and within the third quartile for SPI. The ability of the models in replicating the historical climate variables and the drought indices offers some confidence that the models will be able to project future drought over the basins.

\section{2 | Future projection of drought over the basins}

Figure 7 presents the spatial distribution of projected changes in the drought indices (12-month drought scales: SPEI12 and SPI12) over the two basins at the four GWLs.
With SPEI12, an increase in the magnitude of severe drought (i.e., SPEI12_SDM) is projected over the basins. The spatial distribution of the increase is similar at all the GWLs. A maximum increase is projected over the Sahelian part of the Niger basin (i.e., north of $16^{\circ} \mathrm{N}$ ) while the minimum increase is indicated over the Savanna part. However, over both basins, the value of the increase grows with higher GWLs. For instance, while the increase is about 0.3 at GWL1.5, it is up to 0.5 at GWL3.0. Nevertheless, this projection is only statistically significant over the Sahelian part of the basin. The projected changes in SPI differ from that of SPEI. With SPI, a weak change in severe drought magnitude (SPI12_SDM, i.e., \pm 0.1 ) is projected over the basins and the projection is not statistically significant at any part of the basins. Hence, at GWL1.5, the maximum increase in SPI12_SDM (about 0.1) is lower than that of
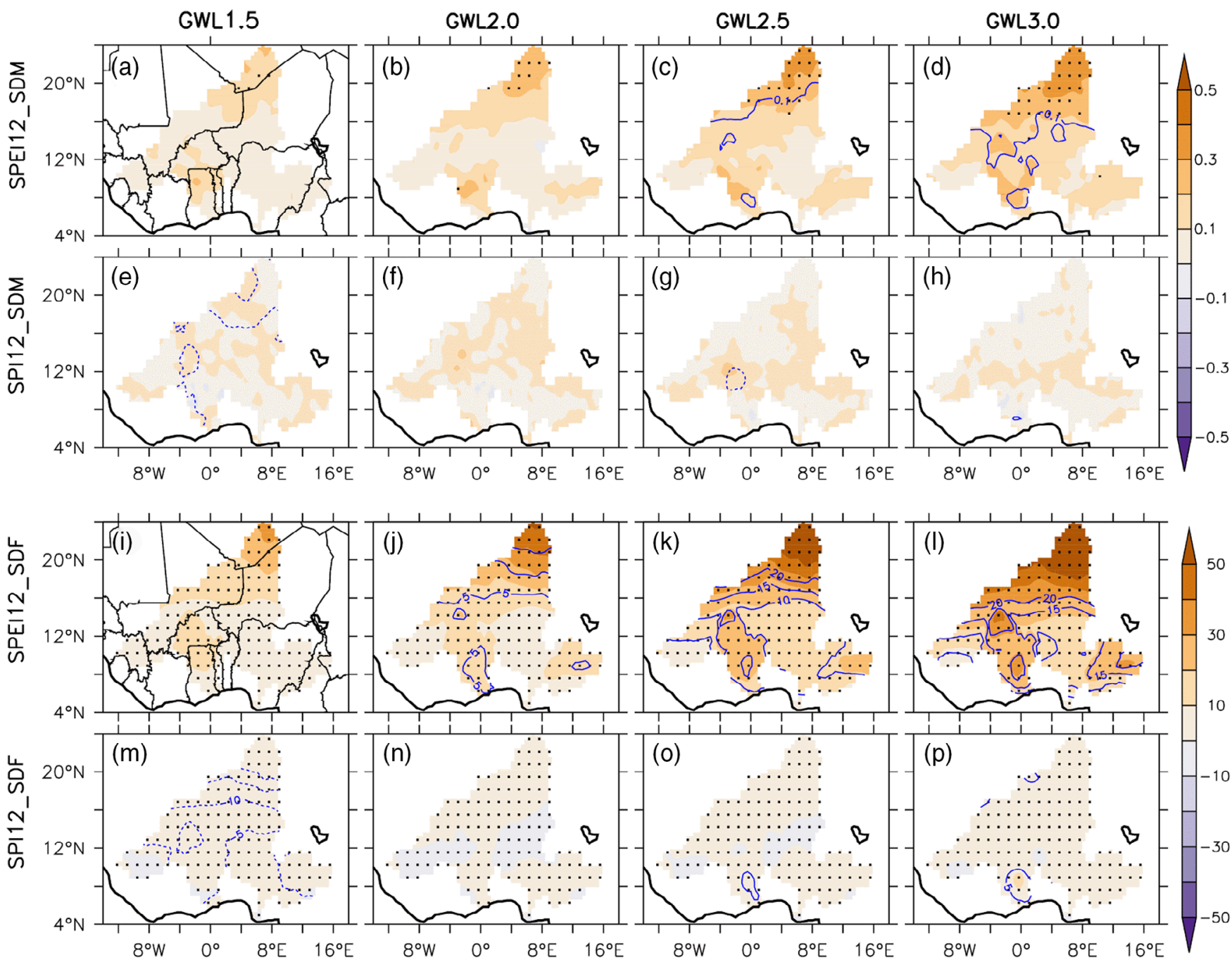

F I G U RE 7 Projected changes in spatial distribution of the magnitude (SDM) and frequency (SDF) of 12-month droughts under different GWLs (GWL1.5, GWL2.0, GWL2.5, and GWL3.0) for SPEI12 and SPI12 over the two river basins [Colour figure can be viewed at wileyonlinelibrary.com] 

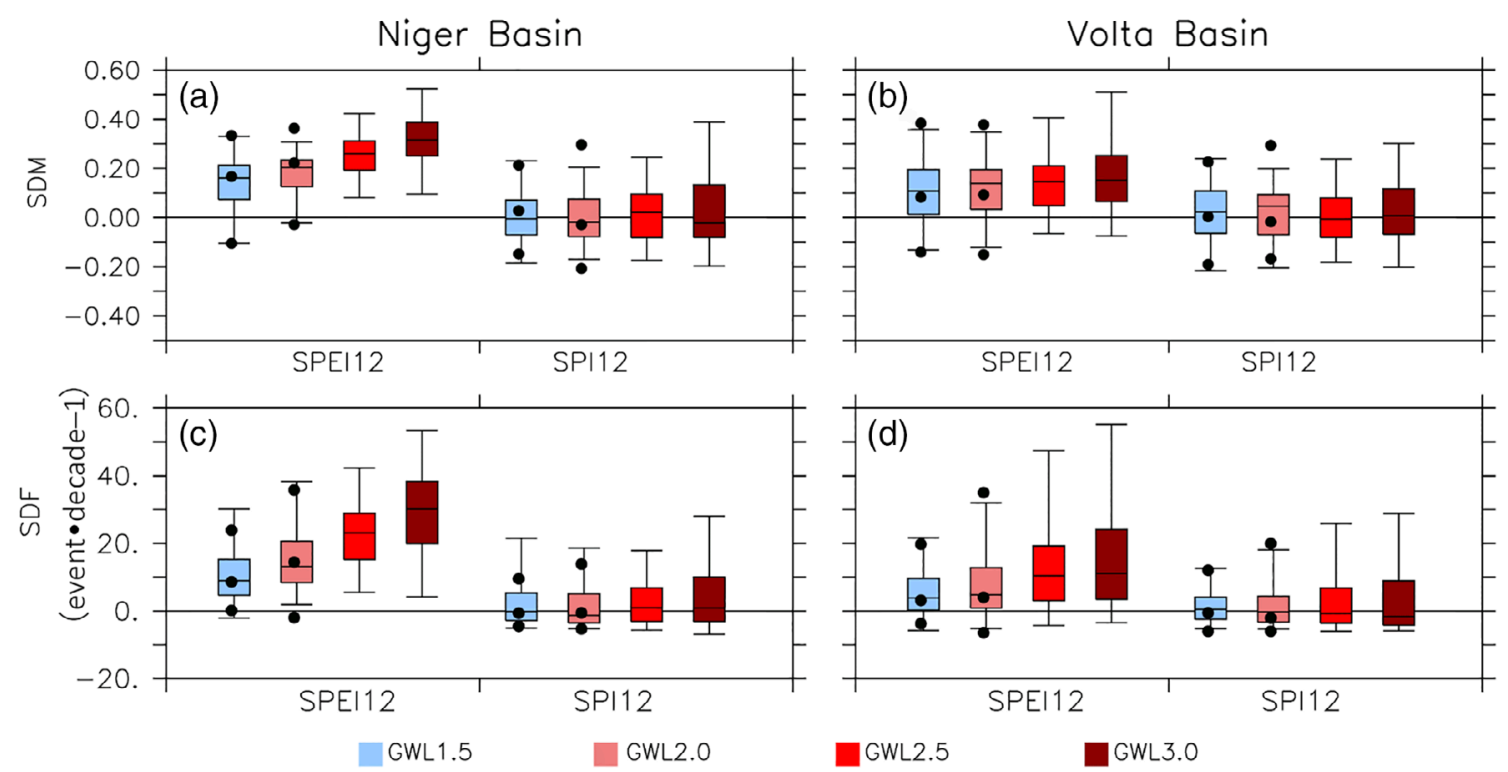

F I G U R E 8 Projected changes in severe drought magnitude (SDM; upper panels) and SDF (lower panels; months·decade ${ }^{-1}$ ), averaged over the basins (NRB and VRB) under different GWLs [Colour figure can be viewed at wileyonlinelibrary.com]

SPEI12_SDM (about 0.3). In addition, unlike SPEI12_SDM, the projected increase in SPI12_SDM does not grow with the increasing GWLs.

The projected changes in SDF also differ for the two drought indices. With SPEI, the models project a substantial increase in SDF (SPEI12_SDF > 10 events.decade ${ }^{-1}$ ) over the entire basins, but with SPI, they project a weaker increase (SPI12_SDF $<10$ events.decade ${ }^{-1}$ ) and even indicate a decrease (about 10 events.decade ${ }^{-1}$ ) over some parts of the basins (Figure 7). In addition, the spatial distribution of the projected changes features a stronger gradient in SPEI12_SDF than in the SPI12_SDF. For instance, at GWL1.5, the change in SPEI12_SDF ranges from 10 events.decade ${ }^{-1}$ at $15^{\circ} \mathrm{N}$ to 30 events.decade ${ }^{-1}$ at $20^{\circ} \mathrm{N}$, but the change in SPI12_SDF is almost constant (about 10 events.decade ${ }^{-1}$ ) north of $15^{\circ} \mathrm{N}$. Furthermore, while higher GWLs enhances the SPEI12_SDF (e.g., from 30 events.decade ${ }^{-1}$ at GWL1.5 to 50 events.decade ${ }^{-1}$ at GWL3.0), it has no influence in SPI12_SDF (which is almost the same at all GWLs). Nevertheless, the projected changes in both SPEI12_SDF and SPI12_SDF are statistically significant at all GWLs.

To show robustness of the projection, Figure 8 presents the simulations spread and agreement on the projections over each of the basins. There is a better agreement among the simulation on SPEI projections than on SPI projections. With SPEI projections, more than $75 \%$ of the simulations agree on the projected increase in the magnitude and frequency of severe drought over each basin at GWL1.5 and GWL2.0, while all the simulations agree on the increase at GWL2.5 and GWL3.0. However, with SPI projections, there is no agreement among the simulations regarding the changes in severe magnitude and frequency over each basin at any GWL. A comparison of these results with those obtained under RCP4.5 climate change scenario (where the data are available: GWL1.5 and 2.0) indicates that the results are not sensitive to the warming scenario. The projected increase in SPEI12_SDF and SPI12_SDF over the basins is also in agreement with Klutse et al. (2018) projections on increased consecutive dry days (CDD), meaning for the increase in dry spells and drought persistency. Frich et al. (2002) showed that CDD is an indicator of short-range drought and drought tendencies.

The distinction between SPEI and SPI projections found here is consistent with results of Abiodun et al. (2018) over southern African basins (Orange, Limpopo, Zambezi, and Okavango). Abiodun et al. (2018) also projected a higher increase in drought intensity and frequency for SPEI than for SPI. They showed that with further warming (i.e., from GWL1.5 to GWL3.0) the rate of increase is faster for SPEI than for SPI and attributed the difference to the influence of global warming PET. Hence, the authors argued that using SPI for future projections may underestimate the severity and frequency of drought over the southern river basins, because SPI does not account for the influence of the PET. The argument is also true over the two West African basins (Niger and Volta) considered here. Historically, West Africa has been ravaged by incessant drought occurrence with socioeconomic consequences. Hence, using the appropriate drought indices to monitor and project drought characteristics will help minimize socioeconomic impacts of future drought over the region. 


\section{4 | CONCLUSION}

As part of ongoing global efforts to understand the possible effects of global warming at specific levels (e.g., from 1.5 to $3.0^{\circ} \mathrm{C}$ ) on the climatology of large basins in West Africa, this paper investigated the potential effects on mean drought index and SDF over Niger and Volta River basins. The multi-model multi-ensemble CORDEX dataset was used in the analysis. The ability of the models to reproduce basic hydroclimatological variables over the study area was determined by comparing the simulations of past years with CRU data. The projected changes in drought characteristics were examined at four GWLs under the RCP8.5 scenario. The conclusion of the results can be summarized as follows:

- The CORDEX simulations realistically reproduce the spatial distribution of all the climatic variables (PRE, PET, CWB, etc.) needed for calculating the drought indices over West Africa and reproduce a credible annual cycle of the variables over each basin.

- Although for both SPEI and SPI, the simulations struggle to reproduce the spatial variation of severe drought magnitude and frequency over West Africa; the simulated values are cluster around observed values over each basin.

- For SPEI, an increase in severe drought magnitude and frequency are projected over the whole basins and the value of the increase grows with higher GWLs. More than $75 \%$ of the simulations agree on this projection.

- The projected changes in severe drought magnitude and frequency are weaker for SPI than for SPEI and the agreement among simulations is also weaker for SPI than SPEI. Hence, using SPI to project future changes in drought characteristics may underestimate the severity and frequency of drought over the basins.

These results can be improved, extended, or applied in several ways to assist the policy makers in reducing the risk of global warming climate on agriculture, water availability, and food security in West Africa. For example, the resolution of the observation (CRU: $0.5 \times 0.5^{\circ}$ ) and simulation datasets (CORDEX: $0.4 \times 0.4^{\circ}$ ) used in the study can be increased to resolve the spatial drought indices better, especially when the higher CORDEX resolution datasets are ready. Example of such higher-resolution datasets used and discussed in Abiodun et al. (2019) and Dieng et al. (2018). Furthermore, the projected changes in this study are only for meteorological droughts. Extending the projections to agricultural and hydrological droughts will give a better quantification of the potential impacts of the global warming levels on agricultural activities and water availability. It will also show how climate change may alter the complex relationships among meteorological, agricultural, and hydrological droughts. However, such projection requires application of hydrological models (e.g., the Soil and Water assessment tool SWAT). The models can also be extended to investigate how different agricultural and water management practices can be used to minimize impacts of meteorological droughts on streamflow and agricultural production. However, the present study has shown how the ongoing global warming may impact meteorological droughts over two river basins in West Africa at different GWLs. It has shown that using only SPI to characterize drought may underestimate the impact of the global warming on future drought projection.

\section{ACKNOWLEDGEMENTS}

The project was supported with grants and bursaries from National Research Foundation (NRF, South Africa) and the Water Research Commission (WRC, South Africa). Computation facilities were provided by Centre for High Performance Computing (CHPC, South Africa). We acknowledge logistic support and data from CORDEX-Africa. We thank the Editor and anonymous reviewers for their constructive comments, which have improved the quality of the paper.

\section{ORCID}

Philip G. Oguntunde (1) https://orcid.org/0000-0003-19636984

Babatunde J. Abiodun (1D https://orcid.org/0000-00023878-0116

Abayomi A. Abatan (1D https://orcid.org/0000-0003-23303322

\section{REFERENCES}

Abatan, A.A., Gutowski, W.J., Jr., Ammann, C.M., Kaatz, L., Brown, B.G., Buja, L., Bullock, R., Fowler, T., Gilleland, E. and Gotway, J.H. (2017a) Multi-year droughts and pluvials over Upper Colorado River basin and associated circulations. Journal of Hydrometeorology, 18, 799-818. https://doi.org/10.1175/ JHM-D-16-0125.1.

Abatan, A.A., Gutowski, W.J., Jr., Ammann, C.M., Kaatz, L., Brown, B.G., Buja, L., Bullock, R., Fowler, T., Gilleland, E. and Halley Gotway, J. (2017b) Statistics of multi-year droughts from the method for object-based diagnostic evaluation (MODE). International Journal of Climatology, 38(8), 3405-3420. https:// doi.org/10.1002/joc.5512.

Abiodun, B.J., Makhanya, N., Petja, B., Abatan, A.A. and Oguntunde, P.G. (2018) Future projection of droughts over major river basins in southern Africa at specific global warming levels. Theoretical and Applied Climatology, 137, 1785-1799. https://doi.org/10.1007/s00704-018-2693-0.

Adeyeri, O.E., Lawin, A.E., Laux, P., Ishola, K.A. and Ige, S.O. (2019) Analysis of climate extreme indices over the KomaduguYobe basin, Lake Chad region: Past and future occurrences. Weather and Climate Extremes, 23, 100194.

Alfieri, L., Bisselink, B., Dottori, F., Naumann, G., de Roo, A., Salamon, P., Wyser, K. and Feyen, L. (2017) Global projections of river flood risk in a warmer world. Earth's Future, 5, 171-182. https://doi.org/10.1002/2016EF000485. 
Andersen, I., Dione, O., Jarosewich-Holder, M. and Olivry, J.C. (2005) The Niger River basin: A vision for sustainable management. Washington, DC: World Bank. Available at: www.worldbank.org.

Beguería, S., Vicente-Serrano, S.M., Reig, F. and Latorre, B. (2014) Standardized precipitation evapotranspiration index (SPEI) revisited: Parameter fitting, evapotranspiration models, tools, datasets and drought monitoring. International Journal of Climatology, 34, 3001-3023. https://doi.org/10.1002/joc.3887.

Diasso, U. and Abiodun, B.J. (2017) Drought modes in West Africa and how well CORDEX RCMs simulate them. Theor. Appl. Climatol, 128(1-2), 223-240.

Dieng, D., Laux, P., Smiatek, G., Heinzeller, D., Bliefernicht, J., Sarr, A., Gaye, A.T. and Kunstmann, H. (2010) Performance analysis and projected changes of agroclimatological indices across West Africa based on high-resolution regional climate model simulations. Journal of Geophysical Research: Atmospheres, 123(15), 7950-7973. https://doi.org/10.1029/2018JD028536.

Droogers, P. and Allen, R.G. (2002) Estimating reference evapotranspiration under inaccurate data conditions. Irrigation and Drainage Systems, 16, 33-45. https://doi.org/10.1023/A:1015508322413.

Frich, P., Alexander, L., Della-Marta, P., Gleason, B., Haylock, M., Klein Tank, A. and Peterson, T. (2002) Observed coherent changes in climatic extremes during the second half of the twentieth century. JSTOR, 19, 193-212.

Guttman, N.B. (1998) Comparing the Palmer drought index and the standardized precipitation index. Journal of the American Water Resources Association, 34, 113-121.

Guttman, N.B. (1999) Accepting the standardized precipitation index: A calculation algorithm. Journal of the American Water Resources Association, 35, 311-322.

Hargreaves, G.L. and Samani, Z.A. (1985) Reference crop evapotranspiration from temperature. Applied Engineering in Agriculture, 1, 96-99.

Harris, I., Jone, P.D., Osborn, T.J. and Lister, D.H. (2014) Updated highresolution grids of monthly climatic observations - the CRU TS310 Dataset Int. J. Climatol. 34623-64. https://doi.org/10.1002/joc.3711

Hulme, M., Doherty, R., Ngara, T., New, M. and Lister, D. (2001) African climate change: 1900-2100. Climate Research, 17, 145-168.

IPCC. (2007) In: Solomon, S., Qin, D., Manning, M., Chen, Z., Marquis, M., Averyt, K.B., Tignor, M. and Miller, H.L. (Eds.) Climate change 2007: The physical science basis: Working Group I contribution to the fourth assessment report of the IPCC. Cambridge, England: Cambridge University Press.

IPCC. (2014) Impacts, Adaptation, and Vulnerability, Part A: Global and Sectoral Aspects: Working Group II to the Fifth Assessment Report of the Intergovernmental Panel on Climate Change. In: Field, C.B., Barros, V.R., Dokken, D.J., Mach, K.J., Mastrandrea, M.D., Bilir, T. E., Chatterjee, M., Ebi, K.L., Estrada, Y.O., Genova, R.C., Girma, B., Kissel, E.S., Levy, A.N., MacCracken, S., Mastrandrea, P.R. and White, L.L. (Eds.). Cambridge, England and New York, NY: Cambridge University Press, p. 1132.

Kasei, R., Diekkrüger, B. and Leemhuis, C. (2010) Drought frequency in the Volta Basin of West Africa. Sustainability Science, 5, 89-97.

Klutse, N.A.B., Ajayi, V.O., Gbobaniyi, E.O., Egbebiyi, T.S., Kouadio, K., Nkrumah, F., Quagraine, K.A., Olusegun, C., Diasso, U., Abiodun, B.J. and Lawal, K. (2018) Potential impact of $1.5^{\circ} \mathrm{C}$ and $2^{\circ} \mathrm{C}$ global warming on consecutive dry and wet days over West Africa. Environmental Research Letters, 13(5), 055013.

Kumi, N. and Abiodun, B.J. (2018) Potential impacts of $1.5^{\circ} \mathrm{C}$ and $2{ }^{\circ} \mathrm{C}$ global warming on rainfall onset, cessation and length of rainy season in West Africa. Environmental Research Letters, 13(5), 055009.
Laux, P., Kunstmann, H. and Bárdossy, A. (2008) Predicting the regional onset of the rainy season in West Africa. International Journal of Climatology, 28, 329-342. https://doi.org/10.1002/joc.1542.

Lloyd-Hughes, B. and Saunders, M.A. (2002) A drought climatology for Europe. International Journal of Climatology, 22, 1571-1592.

McKee, T.B., Doesken, N.J. and Kleist, J. (1993) The relationship of drought frequency and duration to time scales. In: Proceedings of the Eighth Conference on Applied Climatology, 17-22 January, Anaheim, CA. Boston, MA: American Meteorological Society, pp. 179-184.

Nikulin, G., Lennard, C., Dosio, A., Kjellström, E., Chen, Y., Hänsler, A., Kupiainen, M., Laprise, R., Mariotti, L., Maule, C. F. and van Meijgaard, E. (2018) The effects of 1.5 and $2^{\circ}$ of global warming on Africa in the CORDEX ensemble. Environmental Research Letters, 13(6), 065003.

Ogilvie, A., Mahé, G., Ward, J., Serpantié, G., Lemoalle, J., Morand, P., Barbier, B., Diop, A.T., Caron, A., Namarra, R., Kaczan, D., Lukasiewicz Paturel, J.-E., Gaston Liénou, G. and Clanet, J.C. (2010) Water, agriculture and poverty in The Niger River basin. Water International, 5, 594-622.

Oguntunde, P.G., Abiodun, B.J. and Lischeid, G. (2017) Impacts of climate change on hydro-meteorological drought over the Volta Basin. West Africa Global and Planetary Change, 155, 121-132.

Oguntunde, P.G., Friesen, J., van de Giesen, N. and Savenije, H.H. G. (2006) Hydroclimatology of the Volta River Basin in West Africa: Trends and variability from 1901 to 2002. Physics and Chemistry of the Earth, 31, 1180-1188.

Oguntunde, P.G., Lischeid, G. and Abiodun, B.J. (2018) Impacts of climate variability and change on drought characteristics in The Niger River basin, West Africa. Stochastic Environmental Research and Risk Assessment, 32, 1017-1034. https://doi.org/ 10.1007/s00477-017-1484-y.

Oyerinde, G.T., Hountondji, F.C.C., Wisser, D., Diekkrüger, B., Lawin, A.E., Odofin, A.J. and Afouda, A. (2015) Hydro-climatic changes in The Niger basin and consistency of local perceptions. Regional Environmental Change, 15, 1627-1637.

Riahi, K., Rao, S., Krey, V., Cho, C., Chirkov, V., Fischer, G., Kindermann, G., Nakicenovic, N. and Rafaj, P. (2011) RCP 8.5: A scenario of comparatively high greenhouse gas emissions. Climatic Change, 109(1-2), 33-57.

Sylla, M.B., Pal, J.S., Faye, A., Dimobe, K. and Kunstmann, H. (2018) Climate change to severely impact West African basin scale irrigation in $2^{\circ} \mathrm{C}$ and $1.5^{\circ} \mathrm{C}$ global warming scenarios. Scientific Reports, 8(14395), 1-9. https://doi.org/10.1038/s41598-018-32736-0.

UNFCCC, C. (2015). Adoption of the Paris Agreement. I: Proposal by the President (Draf tDecision), Geneva, Switzerland: United Nations Office (s 32).

van de Giesen, N., Liebe, J. and Jung, G. (2010) Adapting to climate change in the Volta Basin. West Africa Current Science, 98(8), 1033-1,038.

Vicente-Serrano, S.M., Beguería, S. and López-Moreno, J.I. (2010) A multiscalar drought index sensitive to global warming: The standardized precipitation evapotranspiration index. Journal of Climate, 23(7), 169-171.

How to cite this article: Oguntunde PG, Abiodun BJ, Lischeid G, Abatan AA. Droughts projection over the Niger and Volta River basins of West Africa at specific global warming levels. Int J Climatol. 2020;40:5688-5699. https://doi.org/10. $\underline{1002 / j o c .6544}$ 